\title{
PATRIMÔNIO CULTURAL E GEOLOGIA DO QUADRILÁTERO FERRÍFERO
}

\author{
Ana Maria Goulart Bustamante, Sideny Ribeiro Gonzalez \\ Instituto Brasileiro de Geografia e Estatística
}

\begin{abstract}
Resumo
O uso inovador do patrimônio cultural pode representar importante componente do crescimento econômico, da coesão social e da sustentabilidade ambiental de um país. Pode-se estimular a inovação criando relações entre a população e bens culturais materiais e imateriais, propondo maneiras de interligar patrimônio cultural e áreas como a geografia física e a geologia, entre muitas possibilidades. Além de enriquecer as pesquisas nesses campos, a utilização do patrimônio histórico e artístico expressa inovação também no ensino de geociências e no geoturismo, novo segmento do turismo voltado para o patrimônio geológico. Estas e outras possibilidades se oferecem no Quadrilátero Ferrífero, região de importância histórica e econômica por seus recursos minerais, especialmente ouro, ferro e a conhecida pedra-sabão, utilizada em construções e esculturas do patrimônio cultural brasileiro e do patrimônio mundial.
\end{abstract}

Palavras-chave: patrimônio cultural, geologia, pedrasabão, Quadrilátero Ferrífero.

\begin{abstract}
The innovative use of historical cultural heritage can represent an important component of economic growth, social cohesion and environmental sustainability of a country. Innovation in the population's relationship with material and immaterial cultural goods can be stimulated, proposing ways to connect cultural heritage and other areas such as physical geography and geology, among many possibilities. Not only enriching the research on cultural Heritage and Geography, the use of cultural heritage means innovation also for teaching earth sciences and for geoturism, a new segment in tourism in which the geological heritage is the main atraction. This and other possibilities can be explored in Quadrilátetro Ferrífero, region of great historical and economic importance due to its mineral resources, especially gold and iron, and soapstone, used in buildings and sculptures of the national and world's cultural heritage.
\end{abstract}

Key words: cultural heritage, geology, soapstone, Quadrilátero Ferrífero.

$\mathrm{O}$ uso inovador do patrimônio histórico cultural pode representar um importante componente do crescimento econômico e da geração de empregos, da coesão social e da sustentabilidade ambiental de um país (GETTING..., 2015). Em vista disso, pode ser estimulada a inovação no relacionamento da população com os bens culturais materiais e imateriais, propondo novas maneiras de interligar o patrimônio cultural e áreas como a geografia física, a geologia e a geomorfologia, entre muitas outras possibilidades. Uma das formas de enriquecer as pesquisas tanto no campo do patrimônio cultural como da geografia poderia ser a utilização do patrimônio histórico edificado como recurso nos estudos de geociências e na educação, como sugerem Ruth Siddall (2016) e Ruchkys e Machado (2013). No Brasil, uma área em especial pode servir de exemplo para essas possibilidades: o Quadrilátero Ferrífero, região de grande importância histórica e econômica devido a seus recursos minerais, em especial ouro e ferro, além da pedra-sabão (ou esteatito), utilizada em construções e esculturas do patrimônio cultural brasileiro e do patrimônio mundial (Figura 1). 


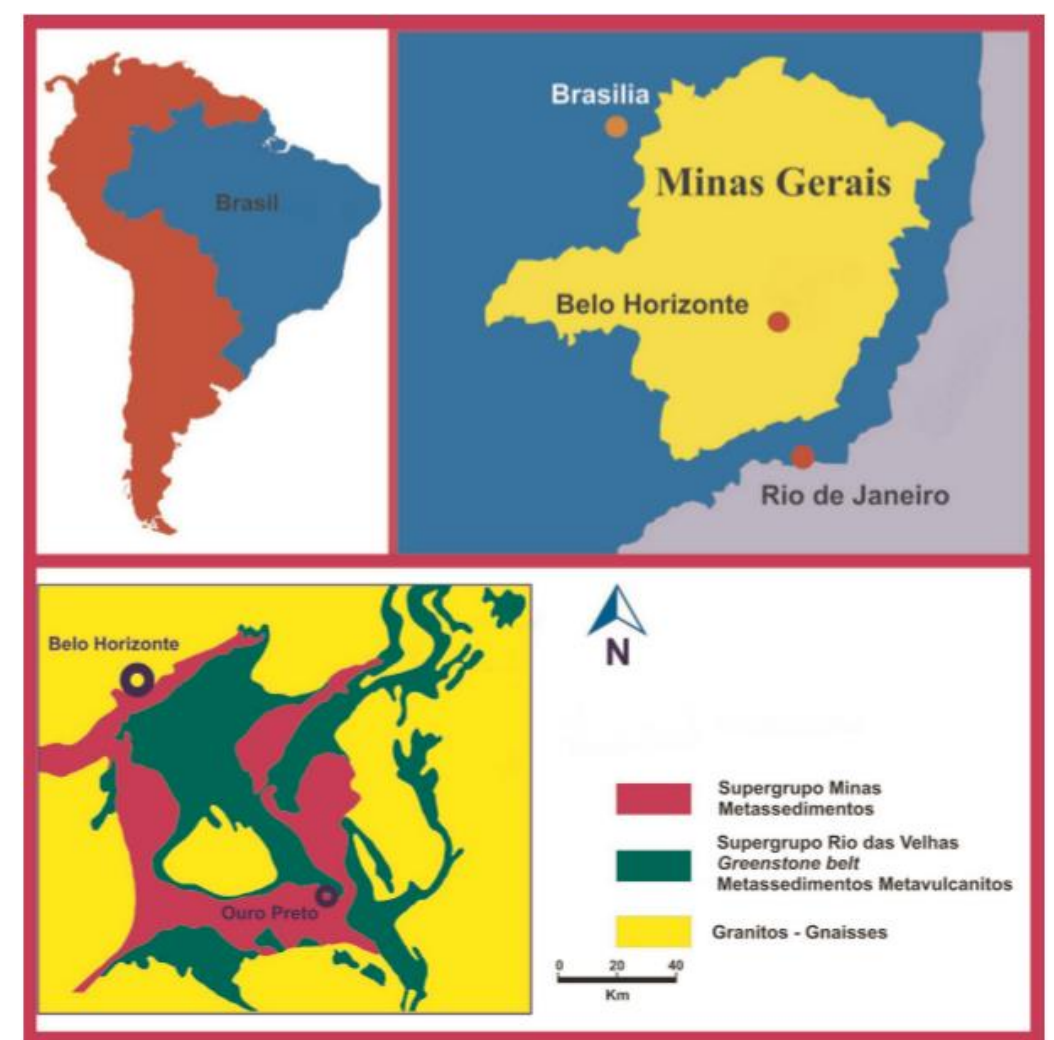

Figura 1. Localização do Quadrilátero Ferrífero. Fonte: Roeser e Roeser (2010).

Área aproximadamente retangular no centro-sul do Estado de Minas Gerais, o Quadrilátero Ferrífero contém recursos minerais significativos, especialmente ouro e ferro, caracterizando-se como uma das principais províncias metalogenéticas do Brasil (AZEVEDO et al., 2012). Com inclusão proposta como geoparque de uma rede internacional de áreas de patrimônio geológico com uso sustentável (GEOPARK..., 2018; AZEVEDO, 2007), o Quadrilátero Ferrífero situa-se na borda limítrofe entre as Províncias Geotectônicas São Francisco e Mantiqueira (Almeida, 1977, apud SILVA, 2007), mais exatamente na parte sul do Cráton São Francisco, pertencente à Província São Francisco, e na porção sudeste da Faixa Araçuaí, localizada na Província Mantiqueira. A Faixa Araçuaí constituía, junto com a Faixa Congo Ocidental, um único orógeno brasilianopanafricano, chamado orógeno Araçuaí-Congo Ocidental, sendo que a Faixa Araçuaí representa a porção brasileira originária do paleocontinente Gondwana (Alkmin et al., 2007, apud FONSECA, 2011).

O contexto estratigráfico do Quadrilátero Ferrífero se caracteriza por três grandes conjuntos de rochas: os complexos metamórficos de rochas cristalinas arqueanas, as sequências do tipo greenstone belt ${ }^{1}$ de idade arqueana (representadas pelo Supergrupo Rio das Velhas) e as sequências metassedimentares paleo e mesoproterozoicas (representadas pelo Supergrupo Minas e Supergrupo Espinhaço). É nas rochas metamáficas e metaultrametamáficas do Grupo Nova Lima, do Supergrupo Rio das Velhas, que se encontram as jazidas de pedra-sabão, na forma de corpos isolados ou em matacões. Em geral, esses depósitos são cobertos por um manto de intemperismo espesso e, para extração da pedra-sabão, é necessário recorrer a escavações (FRANCO et al., 2016).

\footnotetext{
${ }^{1}$ Greenstone belt são regiões que contêm sequências de rochas verdes, como xistos máficos, ultramáficos, formações ferríferas, chert, rochas vulcanoquímicas diversas, de baixo grau metamórfico. São comuns nos terrenos de idade arqueana (4 000 a 2500 Milhões de anos) e representam em grande parte restos da crosta oceânica.
} 
Na região do Quadrilátero Ferrífero, as jazidas de pedra-sabão, ou esteatito, são há tempos utilizadas pelos habitantes, tendo sido encontradas em sítios arqueológicos panelas desse material com 2000 anos de idade (DIAS et al., 2016). Atualmente, é possível encontrar tanto panelas como outras peças de pedra-sabão ofertadas por artesãos locais aos turistas que acorrem à região de Ouro Preto e outras cidades históricas mineiras. Há mais usos da pedra-sabão que ainda hoje justificam sua extração por empresas mineradoras no Quadrilátero Ferrífero, por exemplo, como material refratário para lareiras e fornos.

O Supergrupo Rio das Velhas, onde se encontra o esteatito em Minas Gerais, é uma das principais unidades geológicas do Quadrilátero Ferrífero e é envolto por rochas gnáissicas, graníticas e migmatíticas. Dorr (1969, apud FONSECA, 2011) o subdividiu em Grupo Nova Lima (inferior) e Maquiné (superior). Ladeira (1980a, 1980b apud FONSECA, 2011) admite a subdivisão feita por Dorr, mas subdivide o Grupo Nova Lima, onde se encontram as jazidas de pedra-sabão, em três unidades (da base para o topo): Unidade Metavulcânica, Unidade Metassedimentar Química e Unidade Superior Clástica. É na Unidade Metavulcânica que se encontram derrames ultramáficos-máficos e associações félsicas, com ocorrência de esteatitos (pedra-sabão), mas também serpentinitos, komatítos com textura spinifex, talco xistos, clorita xistos, formação ferrífera bandada, quartzo-carbonato xisto e filitos (LADEIRA \& ROESER, 1983 apud FONSECA, 2011).

O esteatito é um filossilicato de magnésio hidratado e ficou conhecido como pedra-sabão, provavelmente devido a sua maciez e sedosidade percebida ao toque, uma vez que se trata de uma rocha metamórfica ultramáfica composta principalmente de talco $\left(\mathrm{Mg}_{3} \mathrm{Si}_{4} \mathrm{O}_{10}(\mathrm{OH})_{2}\right)$. Em Minas Gerais, é encontrado em cores que variam do cinza ao verde, dependendo de sua composição química, que pode incluir minerais como a dolomita, a actinolita e a lorita. A região dos municípios de Lamin e Senhora dos Remédios, no extremo sul do Quadrilátero Ferrífero, se distingue por apresentar, nas rochas metaultramáficas, o mineral olivina ainda preservado e interpretado como o protólito magmático (JORDT-EVANGELISTA \& SILVA, 2005). Com base nas análises químicas e texturas observadas nas rochas, Jordt-Evangelista e Silva (2005) concluíram que são também pertencentes ao Grupo Nova Lima e que o provável protólito são rochas komatíticas peridotíticas plutônicas, e não komatiítos vulcânicos, como em outras regiões do Quadrilátero Ferrífero. O metamorfismo que afetou essas rochas, sob condições de fácies xisto verde alto a anfibolito baixo durante a infiltração de fluidos aquosos durante o processo metamórfico-metassomático, resultou na transformação daquelas rochas em pedra-sabão e serpentinito.

Ainda segundo Jordt-Evangelista e Silva (2005), na formação do esteatito, o magma de composição komatítica atravessou uma crosta primitiva gnáissica, tanto para derramar-se como rocha vulcânica na superfície quanto cristalizar-se como plutônica nos condutos/fraturas por onde ascendeu. Concluíram, portanto, que os protólitos dessas rochas na região do município de Lamin são peridotitos komatí́ticos de elevados teores de óxido de magnésio (MgO), com cerca de 35\% em peso. No tocante à idade de deposição, datações U-Pb em zircões de lavas félsicas indicam idades de $2776 \mathrm{Ma}$ (milhões de anos) e, nos zircões detríticos e monazitas de unidades sedimentares do topo do supergrupo Rio das Velhas, uma idade máxima de $2857 \mathrm{Ma}$ (ALKMIN \& MARSHAK, 1998).

\section{Patrimônio cultural do Brasil no Quadrilátero Ferrífero}


As cidades históricas situadas na região do Quadrilátero Ferrífero foram o principal foco de atenção ao ser criado no Brasil o órgão nacional do Patrimônio Histórico e Artístico, em 1937. A região sofreu uma forte transformação de sua economia com o esgotamento do ouro, no final do século XVIII, que fez com que Ouro Preto, Mariana e outras cidades dependentes da exploração do metal enfrentassem uma estagnação econômica, o que permitiu manter preservadas suas construções, livres de alterações que normalmente ocorreriam num ambiente economicamente mais dinâmico. No início do século XX, os artistas do movimento modernista "descobriram" as cidades históricas preservadas e contribuíram para que igrejas e prédios públicos fossem tombados já em 1938, momento da criação dos livros do tombo do atual Instituto do Patrimônio Histórico e Artístico Nacional - IPHAN (OLIVEIRA, 2008).

Entre os bens tombados desde 1938, predominam largamente as inscrições no Livro de Belas Artes e no Livro Histórico, que somam, nos primeiros dez anos, 429 bens, dos quais mais da metade (234) no primeiro ano. Desde o início do século XXI, no entanto, a tendência a valorizar bens edificados de origem europeia começou a perder força, principalmente em favor dos bens do Livro do Tombo Arqueológico, Etnográfico e Paisagístico, que tiveram suas inscrições dobradas desde 2000, após um tímido começo em que, nos primeiros dez anos, foram tombados apenas 13 bens, a maior parte dos quais arqueológicos. A instituição, em 2000, do registro de bens culturais de natureza intangível, ou patrimônio cultural imaterial, veio complementar a valorização de riquezas intangíveis, que passaram a ser registradas nos livros de celebrações, saberes, modos de expressão e lugares, estes últimos abrangendo os chamados "lugares culturais", "como mercados, feiras e santuários que abrigam práticas culturais coletivas" (IPHAN, 2018).

No Quadrilátero Ferrífero se pode observar essa transição, pois, após um início marcado pelo tombamento de bens religiosos ditos "de pedra e cal", o IPHAN registrou manifestações culturais como o toque dos sinos em Minas Gerais, no livro de registro das formas de expressão, tendo como referência São João Del Rey e as cidades de Ouro Preto, Mariana, Catas Altas, Congonhas, Diamantina, Sabará, Serro e Tiradentes, e o ofício de sineiro, no livro dos saberes, caracterizando uma nova vertente da valorização da cultura em Minas Gerais (IPHAN, 2017) ao reconhecer o que se pode chamar de paisagem sonora. No Brasil, em 2016, contavam-se 1707 bens materiais tombados, dos quais cerca de 15\% (244 bens) no Estado de Minas Gerais, e 39 bens imateriais registrados, dos quais pelo menos três em Minas (quase 8\%). Os bens culturais materiais incluem desde afrescos e esculturas até grandes conjuntos arquitetônicos como os de Ouro Preto e Mariana. A pesquisa em vários campos e mesmo em áreas de estudo interdisciplinares pode contribuir para o reconhecimento de mais bens culturais que reúnem condições para serem contemplados tanto nos livros do tombo como nos livros de registro.

\section{Geologia e patrimônio cultural em Minas Gerais}

A geologia desempenhou papel fundamental na história e na cultura brasileira desde o fim do século XVII, quando o ouro foi descoberto na região das cidades históricas de Minas (SANTOS, 1976), no Quadrilátero Ferrífero. Para além da marca cultural impressa na própria toponímia do Estado de Minas Gerais (e no seu gentílico - mineiro), a geologia e a atividade mineradora marcaram fortemente as manifestações culturais do período, quando floresceu a arte barroca, represen- 
tada nas construções religiosas dos primeiros povoamentos. Transplantado da Europa para as colônias da América, o barroco ganhou forte expressão e características peculiares na colônia brasileira (OLIVEIRA, 2008) devido, entre outros motivos, à distância da metrópole e às dificuldades de transporte (CAPANEMA, 2016), que levaram ao uso de materiais locais, como o ouro e o esteatito, rocha mais conhecida nesse contexto como pedra-sabão.

São típicos do estilo barroco em Minas os interiores de igrejas entalhados em madeira e recobertos de ouro, além de cantaria, ou seja, placas de soleiras e pisos, em pedra-sabão. A cantaria atingiu sua excelência em Minas, século XVIII e das antigas vilas do ouro que tiveram sua arquitetura marcada pela arte da cantaria Ouro Preto é a que se destaca pela quantidade e qualidade desse tipo de obra (PEREIRA et al., 2004). O reconhecimento da necessidade de preservar essa riqueza cultural fez com que Ouro Preto fosse declarada monumento nacional em 1933 e depois tombada, primeiramente no Livro do Tombo das Belas Artes (em 1938) ${ }^{2}$ e depois no Livro do Tombo Arqueológico, Etnográfico e Paisagístico (em 1986). Ainda, em 1980, o conjunto histórico e arquitetônico de Ouro Preto tornou-se o primeiro bem cultural brasileiro a ser incluído na Lista do Patrimônio Mundial da Organização das Nações Unidas para a Educação, a Ciência e a Cultura - UNESCO.

A pedra-sabão foi utilizada em cantarias de construções do período, mas é especialmente apreciável nas esculturas dos doze profetas, de autoria de Antônio Francisco Lisboa, conhecido como Aleijadinho, instaladas no Santuário de São Jesus de Matosinhos, na cidade mineira de Congonhas. O conjunto das esculturas foi tombado pelo patrimônio artístico em 1939 e, em 1985, foi incluído na lista do Patrimônio Mundial da UNESCO. As linhas sinuosas verificadas nas esculturas dos profetas encontraram na pedra-sabão sua máxima expressividade pela excelência do artista. Em razão de seu baixo grau de dureza ${ }^{3}$, o esteatito oferece condições para esculpir os detalhes e as curvas características do período barroco presentes também em medalhões, imagens, apliques e balaústres. Devido não apenas a sua maciez, mas também a sua resistência, o esteatito é o tipo de rocha com maior representatividade nas fachadas e esculturas do período barroco, seguido pelos quartzitos e, em menor proporção, pelos xistos, que compõem os elementos estruturais das edificações (SILVA, 2007).

Assim, a inovação representada pela associação de abordagens voltadas para bens do patrimônio cultural e estudos de geociências permite dar a entender e a apreender determinados aspectos inexplorados quando não se contemplam as possibilidades oferecidas pelo olhar que abarca temas de várias disciplinas diferentes. Do mesmo modo que a abordagem geológica do material utilizado por Aleijadinho permite compreender de forma inovadora sua arte e o período barroco em que se insere, ao associar geologia e patrimônio cultural artístico, também a abordagem que contempla o patrimônio cultural pode trazer ideias inovadoras para um melhor aproveitamento e para a exploração sustentável do esteatito, material ainda hoje utilizado na fabricação de pedras refratárias e peças artesanais, mas exposto ao perigo de extinção naquela área e nas poucas outras áreas em que ocorre no território brasileiro, em caso de exploração não sustentável.

\footnotetext{
2 Também em 1938 foram inscritos no Livro do Tombo das Belas Artes os conjuntos arquitetônicos das cidades históricas mineiras de Tiradentes, Serro, Mariana, Diamantina e São João Del Rei, situadas na mesma região do Quadrilátero Ferrífero.

${ }^{3} \mathrm{Na}$ escala de Mohs, usada para classificar os minerais conforme sua dureza relativa (de 1 a 10, a mais dura), o esteatito é rocha do grau mais baixo, ou seja, menos dura.
} 
Não apenas os bens artísticos ou edificados, mas muitos outros bens culturais podem ser associados de forma mais direta a estudos voltados para a sustentabilidade de todos os pontos de vista. Constitui uma inovação, por exemplo, a abordagem científica, turística ou educacional dos bens do menos conhecido livro do tombo arqueológico, etnográfico e paisagístico, o qual tem recentemente apresentado crescimento na quantidade de tombamentos. Esse livro inclui muitas feições geográficas reconhecidamente importantes do ponto de vista geológico e geomorfológico, mas também cultural histórico e paisagístico. Esse é o caso de formações rochosas como aquelas entremeadas com áreas urbanizadas e vegetação preservada responsáveis pelo desenho da paisagem cultural da cidade do Rio de Janeiro, que a UNESCO em 2016 reconheceu no âmbito do Patrimônio Mundial.

Muitas formações, como Pão de Açúcar, Corcovado, Pedra da Gávea, além de praias e outras feições naturais cariocas, individualmente ou em conjunto, foram tombadas e constituem valioso atrativo turístico nacional e mundialmente, mas sua atratividade em alguns casos pode se estender além do patrimônio paisagístico e alcançar também o patrimônio geológico, como é o caso do Pão de Açúcar, por exemplo, o qual ostenta ainda o título de sítio geológico reconhecido pela Comissão Brasileira de Sítios Geológicos e Paleobiológicos (SIGEP), condição que atrai atividades científicas, de geoturismo e de educação. Os sítios geológicos são áreas onde há ocorrências geológicas muito especiais e importantes, que registram a origem e a evolução da Terra naqueles locais ou apresentam beleza natural notável. São preservados e protegidos de alterações em sua configuração, podendo, no entanto, ser utilizados em iniciativas de pesquisa científica ou de educação. Recentemente, o geoturismo tem sido um outro uso em exploração, que é um novo segmento do turismo que tem áreas geologicamente relevantes como principal atração. No Estado do Rio de Janeiro, seu Serviço Geológico (Departamento de Recursos Minerais - DRM), mantém o Projeto Caminhos Geológicos para destacar e preservar monumentos geológicos, como museus ao ar livre, através de placas que contam sua evolução histórica.

A catalogação e descrição dos sítios geológicos brasileiros feita pela SIGEP contribui para evitar a perda de um patrimônio geológico rico e se insere na linha programática da UNESCO de preservação do patrimônio natural da humanidade por meio de sua valorização e uso inovador para, citando apenas algumas possibilidades propostas, estudos e pesquisa científica e geoturismo. No Quadrilátero Ferrífero, foram catalogados o Pico do Itabira e a Serra da Piedade. O primeiro inicialmente como um marco geográfico para os bandeirantes nos séculos XVII e XVIII, e o segundo, além de estar associado à história pelos bandeirantes, exposições de rochas itabiritos da Formação Cauê, do Supergrupo Minas, também é um referencial religioso com a construção da primeira capela (Azevedo et al. 2009). Segundo esses autores, em 1956 o IPHAM tombou parte do conjunto paisagístico e arquitetônico da Serra da Piedade e em 2005, o Instituto Estadual do Patrimônio Histórico e Artístico (IEPHA - MG) ampliou seu perímetro de proteção. Há um grande ganho em perspectivas quando se associam o título do IPHAN e da SIGEP ou da UNESCO.

Encontram-se, por todo o território brasileiro, feições tombadas pelo Patrimônio Cultural que permitiriam uma infinidade de estudos interdisciplinares e usos inovadores, especialmente no pouco explorado livro do tombo arqueológico, etnográfico e paisagístico. No Quadrilátero Ferrífero, especificamente, encontra-se grande quantidade de bens históricos e artísticos, mas é no livro do tombo arqueológico, etnográfico e paisagístico que se inclui, por exemplo, o pico do Itacolomi, na mesma região de Minas Gerais, ponto de referência da região e sítio de interesse internacional 
do ponto de vista científico, educativo, estético, cultural, religioso, histórico e turístico (RUCHKYS \& MACHADO, 2013). No Brasil inteiro se encontram bens dessa categoria, os quais foram tombados por seu valor cultural paisagístico, podendo ser usados em estudos ou no ensino das geociências por seu interesse ambiental mas também porque a condição de bem reconhecido pelos órgãos de patrimônio nacional ou mundial aumenta o potencial de impacto e as possibilidades de exploração interdisciplinar e inovadora dos temas a eles relacionados, contribuindo ainda para a reflexão relativa a métodos sustentáveis no uso de recursos ambientais.

Submetido em 13 de novembro de 2017. Aceito para publicação em 31 de janeiro de 2018. 
ALKMIN, F.F., MARSHAK, S. Transamazonian orogeny in the Southern São Francisco craton region, Minas Gerais, Brazil: evidence for paleoproterozoic collision and collapse in the Quadrilátero Ferrífero. Precambrian Research, v. 90, n.1-2, p.29-58, jun. 1998.

AZEVEDO, U.R. Patrimônio geológico e geoconservação no Quadrilátero Ferrífero, Minas Gerais: potencial para a criação de um Geoparque da Unesco. Tese de doutorado. Belo Horizonte: Universidade Federal de Minas Gerais, 2007.

AZEVEDO, U.R., RENGER, F.E., NOCE, C.M., MACHADO, M.M.M. Serra da Piedade, Quadrilátero Ferrífero, MG. In WINGE, Manfredo. Sítios geológicos e pelontológicos do Brasil / Manfredo Winge (Ed.) ... [et al.]. 2. ed. Brasília: CPRM, 2009. vol 2. : il. ; $30 \mathrm{~cm}$ - p. 203-212.

AZEVEDO, U.R et al. Geoparque Quadrilátero Ferrífero (MG), Proposta. In SCHOBBENHAUS, C., SILVA, C.R. (orgs.) Geoparques do Brasil. Propostas. Volume 1. Brasília: CPRM - Serviço Geológico do Brasil, 2012.

CAPANEMA, C.M. A mineração e a mata: água, madeira e técnica na exploração do ouro nas Minas Gerais setecentistas. In CABRAL, D.C. e BUSTAMANTE, A.G. (orgs.). Metamorfoses florestais. Culturas, ecologias e as transformações históricas da Mata Atlântica. Curitiba: Editora Prismas, 2016.

DIAS, M.R.A.C., LOPES, V.C.P., SALES, R.B.C. Panela mineira de pedra sabão: aspectos históricos, da cultura material e design. $12^{\circ}$ P\&D 2016 Congresso Brasileiro de Pesquisa e Desenvolvimento em Design. Blucher Design Proceedings, v. 9, n.2, out. 2016.

FONSECA, G.M. Petrogênese de rochas ultramáficas do quadrilátero ferrífero e adjacências e sua relação genética com rochas metaultramáficas do tipo serpentinito e esteatito. Dissertação de mestrado. Ouro Preto: Universidade Federal de Ouro Preto, 2011.

FRANCO, A.R., RUCHKYS, U.A., DEUS, J.A.S. Mapeamento participativo e análise dos valores da geodiversidade com artesãos em pedra-sabão da região de Ouro Preto - Minas Gerais. Revista Brasileira de Cartografia, n. 68/3: pp.457-469, mar-abr 2016.

GEOPARK Quadrilátero Ferrífero. Rede Mundial de Geoparks. Disponível em http://www.geoparkquadrilatero.org/?pg=geopark\&id=96. Acesso em 20 fev. 2018.

GETTING cultural heritage to work for Europe. Report on the Horizon 2020 Expert Group on Cultural Heritage. Bruxelas: European Commission, 2015.

INDICADORES de Desenvolvimento Sustentável 2015. Rio de Janeiro: IBGE, 2016.

INSTITUTO do Patrimônio Histórico e Artístico Nacional. Lista de bens tombados e processos de tombamento em andamento (atualização em 25/11/2016). Brasília DF: IPHAN, 2017.

INSTITUTO do Patrimônio Histórico e Artístico Nacional. Patrimônio imaterial. Brasília DF: IPHAN, 2018. Disponível em http://portal.iphan.gov.br/pagina/detalhes/234. Acesso em 14 jan. 2018.

JORDT-EVANGELISTA, H. e SILVA, M.E. Rochas metaultramáficas de Lamin, sul do Quadrilátero Ferrífero, MG: contribuição ao conhecimento do protólito da pedra-sabão. Revista Escola de Minas, vol. 58, n. 1, Jan./Mar. 2005. 
LOPES, L.S.O., ARAÙJO, J.L. e CASTRO, A.J.F. Geoturismo: Estratégia de Geoconservação e de Desenvolvimento Local. Caderno de Geografia, v.21, n.35, 2011.

OLIVEIRA, L.L. Cultura é patrimônio: um guia. Rio de Janeiro: Fundação Getúlio Vargas, 2008.

PEREIRA, C.A., FERNANDES, S.M.S., SILVA, F.G., OLIVEIRA, H., JÚNIOR, A.N. Educação patrimonial: Revisitando Ouro Preto através da cantaria Anais do $2^{\circ}$ Congresso Brasileiro de Extensão Universitária. Belo Horizonte: UFMG, 2004. Disponível em https://www.ufmg.br/congrext/Cultura/Cultura1.pdf. Acesso em 12 mar. 2018.

ROESER, H. M. P. \& ROESER, P. A. "O quadrilátero ferrífero - MG, Brasil: aspectos sobre sua história, seus recursos naturais e problemas ambientais relacionados". Geonomos 18(1): 33-37. 2010

RUCHKYS, U.A. e MACHADO, M.M.M. Patrimônio geológico e mineiro do Quadrilátero Ferrífero, Minas Gerais - Caracterização e iniciativas de uso para educação e geoturismo. Boletim Paranaense de Geociências, vol. 70, 2013.

SANTOS, J.F. Memórias do Distrito Diamantino da Comarca do Serro Frio. Belo Horizonte: Editora Itatiaia; São Paulo: Ed. da Universidade de São Paulo, 1976. 4a edição. Coleção Reconquista do Brasil, v. 26.

SIDDALL, R. The Built Environment as a Geological Resource: Science and Heritage. Abstract. Disponível em http://geoscience.wales/wp-content/uploads/2016/10/GeoscienceWales-Nov-2016-Abstract-and-bio-1.pdf. Acesso em 4 set. 2017.

SILVA, M.E. Avaliação da susceptibilidade de rochas ornamentais e de revestimento à deterioração - um enfoque a partir do estudo em monumentos do Barroco Mineiro. Tese de doutorado. Belo Horizonte: Universidade Federal de Minas Gerais, 2007. 